

\section{SOBRE AS AUTORAS}

Julyana da Silva Lima | julyana.slima.jl@gmail.com

Lattes: http://lattes.cnpq.br/9386513301725515

Graduada em Arquitetura e Urbanismo pela Universidade Estadual do Maranhão - UEMA (2016) e formação técnica em Design de Produto pelo Instituto Federal de Educação, Ciência e Tecnologia do Maranhão - IFMA Campus Monte Castelo (2011). Atualmente, cursa o Mestrado em Design da Universidade Federal do Maranhão UFMA na linha de pesquisa Design e Sustentabilidade (Materiais, Processos e Tecnologias). Possui experiência na área de Arquitetura, Urbanismo e Design de Produto, com interesse e estudos nas temáticas: habitação popular, materiais sustentáveis e técnicas construtivas sustentáveis.

Ingrid Gomes Braga | ingridbraga69@gmail.com

Lattes: http://lattes.cnpq.br/0173410812578164

Possui graduação em Desenho Industrial pela Universidade Federal do Maranhão (1994) e doutorado em Conservação e Restauração de Bens Culturais - Universidad Politécnica de Valencia (2004). Atualmente é professor adjunto da Universidade Estadual do Maranhão. Tem experiência na área de conservação, restauração e mapeamento de riscos do patrimônio cultural, metodologias participativas, arquitetura sustentável.

Atualmente desenvolve projetos na área de Bioarquitetura. 


\title{
Bioarquitetura: sistemas produtivos de mínimo impacto ambiental aplicados ao planejamento de habitações em áreas de risco
}

\author{
Bioarchitecture: Production systems with \\ minimum environmental impact applied \\ to the planning of housing in risk areas
}

Julyana da Silva Lima, Ingrid Gomes Braga

\section{Resumo}

Nos últimos anos, ascende uma preocupação mundial frente aos problemas sociais decorrentes de desastres naturais que afetam o funcionamento eficiente das cidades. No Brasil, é notável o aumento progressivo de pessoas que possuem baixa qualidade de vida por habitarem em áreas de risco ou áreas precárias vulneráveis a desastres. 0 artigo é decorrente de uma pesquisa exploratória que tem como objetivo discutir sobre o panorama das áreas de risco em São Luís - MA, sobre a necessidade de estudos que visem a resiliência das cidades e a disseminação das técnicas construtivas baseadas na Bioarquitetura como possível solução para áreas em que há a possibilidade de conviver com os riscos. Dessa forma, realiza-se um levantamento de dados locais e globais sobre as áreas de riscos e a análise de referências projetuais e soluções sustentáveis. Como resultado, busca-se estimular o estudo e aplicação das técnicas construtivas com redução de custos e impactos ambientais na apropriados para a realidade local.

Palavras-chave: Áreas de risco; Resiliência; Bioarquitetura.

\section{Abstract}

In recent years, there has been a worldwide concern about the social problems arising from natural disasters that affect the efficient functioning of cities. In Brazil, there is a notable increase in the number of people who have a poor quality of life because they live in areas of risk or precarious areas vulnerable to disasters. The article is the result of an exploratory research that aims to discuss the panorama of risk areas in. In the need of studies that aim at the resilience of cities and the dissemination of constructive techniques based on Bioarchitecture as a possible solution for areas where there is the possibility of living with the risks. Thus, a survey of local and global data on the areas of risks and the analysis of project references and sustainable solutions is carried out. As a result, the aim is to stimulate the study and application of construction techniques with reduction of costs and environmental impacts in those appropriate to the local reality.

Keywords: Risk areas; Resilience; Bioarchitecture. 


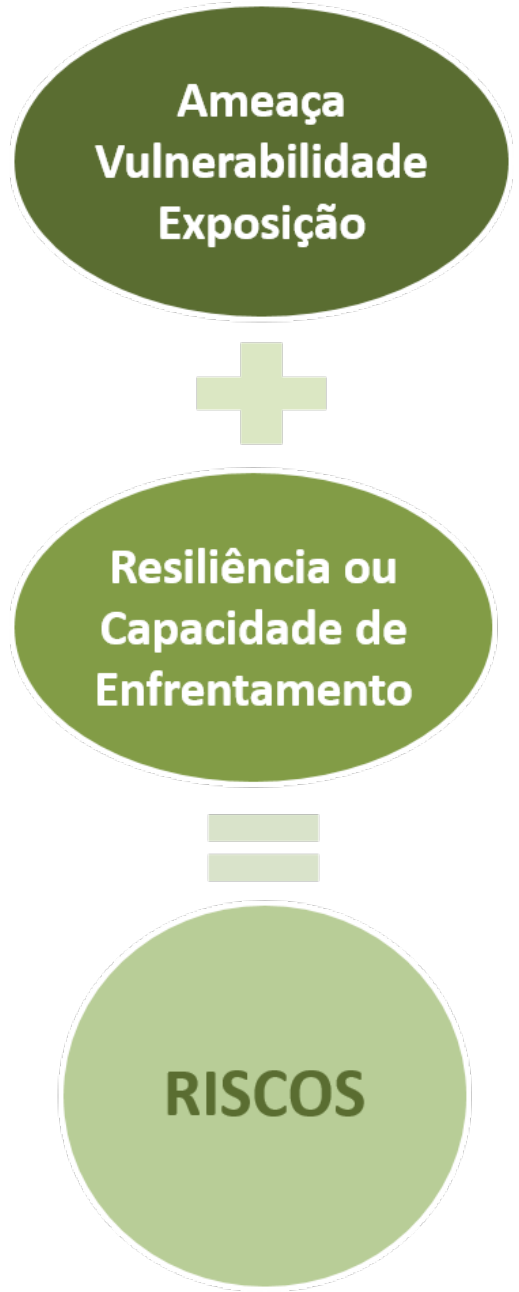

Figura 1: Conceito de risco. Fonte: Produção da autora.

\section{INTRODUÇÃO}

O meio ambiente sofre com os impactos degradantes e as alterações na sua dinâmica natural por inúmeras causas. 0 desenvolvimento urbano acelerado e desordenado aliado à falta de planejamento urbano, constituem uma das principais ameaças que potencializam a intensidade e a frequência dos riscos já existentes, tornando-os mais suscetíveis.

Ponderam-se encostas de morros e áreas alagáveis como locais propícios a desastres naturais, tais como deslizamentos e inundações. Contudo, é perceptível a quantidade de ocupações localizadas em áreas formais ou legais nas cidades que estão submetidas às situações de risco, sendo estes de caráter iminente ou apenas potencial. Tais áreas constituem o foco deste estudo. Sabendo-se ainda que inúmeras dessas áreas são impróprias para habitação, em decorrência da fragilidade ou instabilidade do terreno, seja por ação natural ou antrópica, faz-se necessário o planejamento e gestão de riscos.

Considera-se o risco como probabilidade de danos e perdas futuras, sendo uma combinação entre ameaças (naturais ou antrópicas), vulnerabilidade (propensão de perda ou dano) e exposição ao dano. Todavia, essa combinação não é estática, articula-se dependendo da capacidade de enfrentamento individual ou coletiva (resiliência) na redução dos riscos (Lavell, 1996). As áreas de risco, portanto, são suscetíveis à ocorrência de incidentes perigosos, necessitando de uma solução eficaz a fim de reduzir e controlar seus efeitos. A Figura 1 abaixo esquematiza o conceito de riscos:

Devido ao alarmante número de acidentes naturais e danos por eles provocados, a Organização das Nações Unidas (ONU) aprovou a Resolução n. 44/236 (1989), que marcou o ano de 1990 como o início da Década Internacional para Redução dos Desastres Naturais, com a finalidade principal de redução das perdas de vidas, danos e transtornos socioeconômicos nos países em desenvolvimento. Conforme a ONU (PNUD, 2004), cerca de 75\% da população mundial se encontra em situação de risco de desastres provocados por fenômenos naturais, sendo que estes podem ser intensificados pelo mau uso do solo, ocupação desordenada e desmatamento. Infelizmente, o descaso por parte de autoridades com a segurança pública e ambiental levam à escassez de dados gerais mais atuais sobre o panorama das áreas de riscos. 
As áreas de risco são também consequência da falta de arquitetura e urbanismo para todos. O Brasil arca com uma lógica urbana contraditória ao produzir espaços de qualidade em limitadas áreas das cidades e não ofertar aos desfavorecidos o direito básico à moradia. No entanto, os meios técnicos referentes à arquitetura e urbanismo existem e são excelentes instrumentos. A sustentabilidade aplicada às soluções em áreas de risco possui um desempenho eficiente na mitigação de desastres e na promoção de qualidade de vida.

O estudo em questão serve de base para uma futura fomentação de estudos que abordem soluções voltadas para as áreas de risco. No momento presente, busca-se apenas um embasamento teórico através de uma ramificação da arquitetura que busca equilibrar os impactos da construção à preservação do meio ambiente, baseando-se nos aspectos da sustentabilidade: resiliência dos materiais, baixo custo e mínimo impacto ao meio ambiente (Figura 2).

\section{METODOLOGIA}

De acordo com a classificação disposta pelas regras da metodologia científica, a pesquisa pode ser classificada como uma pesquisa aplicada que busca alcançar conhecimentos para a aplicação prática, mas também de caráter exploratório por esclarecer e desenvolver conceitos, através de pesquisa bibliográfica, levantamento de dados quantitativos, entrevistas e referencias projetuais.

Portanto, visando fundamentar uma significativa base teórica para a pesquisa e alçar os objetivos propostos, a metodologia adotada desde 0 início do segundo semestre de 2015 divide-se em três fases. Segue abaixo o esquema explicativo das fases referentes abaixo (Figura 3):

$1^{\text {a }}$ Fase: Consiste no embasamento teórico e aprofundamento da temática. Nesta etapa são abordados conceitos de riscos, dados quantitativos, justificativas de aplicação, estudos acerca das cidades resilientes, dentre outros. Além da realização de pesquisas e entrevistas na SEMOSP (Secretaria Municipal de Obras e Serviços Públicos).

É importante ressaltar que na fundamentação teórica destacam-se os autores abaixo:

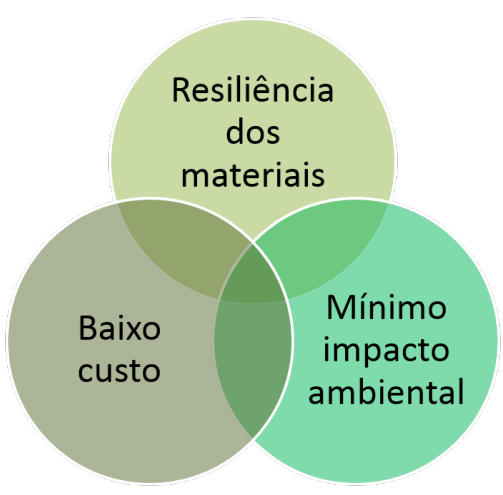

Figura 2: Aspectos da Bioarquitetura. Fonte: Produção da autora.

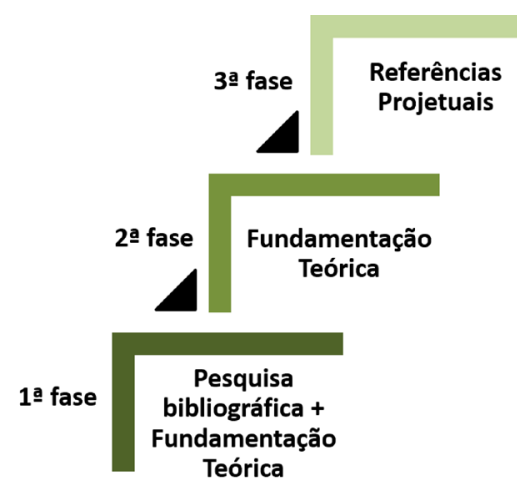

Figura 3: Metodologia. Fonte: Produção da autora. 
- Allan Lavel, que trata sobre os riscos e desastres urbanos analisando a degradação ambiental.

- Miguel A. Sattler, que apresenta a temática do desenvolvimento sustentável sob a ótica da concepção de edificações e comunidades sustentáveis.

- Johan Van Lengen que trata das técnicas e práticas de construções de mínimo impacto ambiental com soluções projetuais e especificidades arquitetônicas, enfatizando a aplicabilidade da Bioarquitetura nas mais diversas áreas.

- Gauzin-Muller, que aborda sobre a arquitetura ecológica.

- Greg Kats, que analisa com profundidade aspectos relacionados a custos, benefícios e estratégias para tornar mais sustentável o mundo que construímos.

- $2^{\mathbf{a}}$ Fase: Esta fase foi realizada através de pesquisas dos principais materiais alternativos naturais e técnicas construtivas tradicionais sustentáveis aplicadas nas construções no Brasil e em diversas partes do mundo, respaldando a possibilidade de construção de tais edificações na cidade de São Luís. Trata-se do aprofundamento da fundamentação teórica, porém voltada totalmente para o universo das propostas construtivas da Bioarquitetura.

- $3^{\circ}$ Fase: A última etapa é resumida à exemplificação de projetos com práticas baseadas na Bioarquitetura que proporcionam resiliência às comunidades e que já tiveram sua viabilidade comprovada. Portanto, esta fase consiste no levantamento de referências projetuais que contemplem práticas de mínimo impacto ambiental e que previnam ou eliminem os riscos presentes em áreas habitacionais.

\section{SÃo LUÍS E OS RISCOS}

A cidade de São Luís, localizada na ilha de Upaon-Açu, no Atlântico Sul, entre as baías de São Marcos e São José de Ribamar, capital do estado do Maranhão, conta com uma área de $834,785 \mathrm{~km}^{2}$ (Figura 4). Segundo dados do Instituto Brasileiro de Geografia e Estatística (IBGE, 2017), a capital maranhense ocupa $15^{\circ}$ lugar no ranking dos municípios mais populosos do Brasil com 1.082.935 habitantes. 


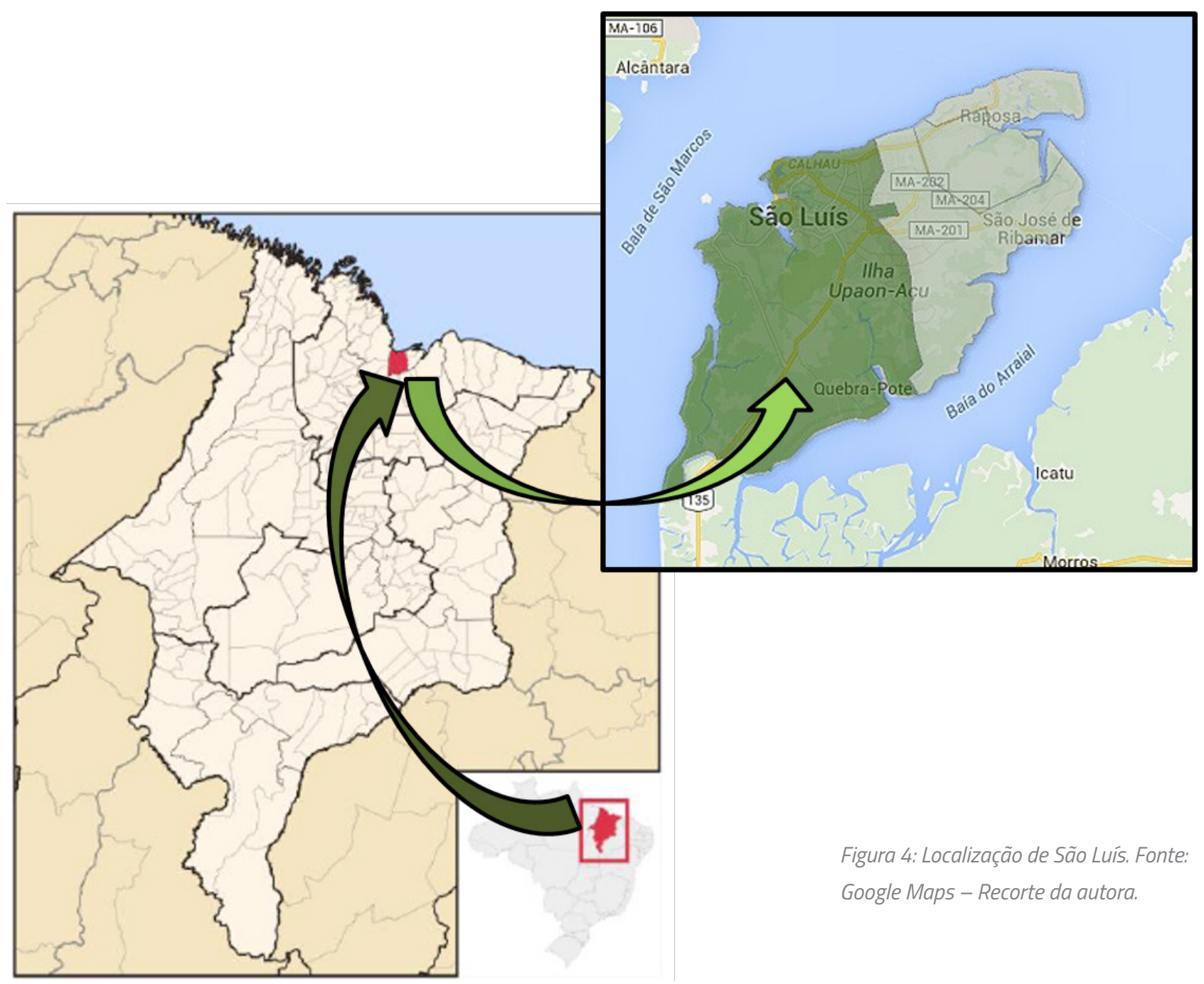

Com todas as pesquisas realizadas através dos órgãos e profissionais competentes, cujo trabalho visa a identificação, prevenção, tratamento e solução dos riscos, chegou-se à conclusão que em São Luís não há nenhuma experiência documentada de atuação efetiva no combate aos riscos em áreas habitacionais de maneira sustentável.

Além disso, não existem estudos e propostas para as habitações localizadas em tais áreas, desconsiderando totalmente uma solução projetual que permita a permanência de comunidades nas áreas em que existe a possibilidade de conviver com os riscos.

A falta de recursos, técnicas adequadas e experiências na atuação, concomitantemente a ausência de conscientização educativa, tornam os riscos mais preocupantes e seus efeitos mais devastadores. 


\begin{tabular}{|l|c|}
\hline \multicolumn{2}{|c|}{ ÁREAS DE RISCO EM SÃO LUís } \\
\hline ANO & QUANTIDADE (Und) \\
\hline 2013 & 66 \\
\hline 2014 & 60 \\
\hline 2016 & 60 \\
\hline
\end{tabular}

Figura 5: Levantamento quantitativo de áreas de risco em São Luís - MA. Fonte: Defesa Civil Municipal (2016).
Segundo a Secretaria Municipal de Obras e Serviços Públicos (SEMOSP), as áreas de risco da cidade são classificadas em: desabamento (como exemplo, casarões no Centro Histórico), deslizamento (áreas ocupadas em encostas) e alagamento (áreas próximas a córregos que anteriormente eram rios Figura 5).

Segundo dados da Defesa Civil Municipal (2016), São Luís possui 60 áreas de risco, sendo um com risco de desabamento, dois que suscetiveis a deslizamentos de terra e cinquenta e sete pontos de alagamentos. As áreas decretadas como estado de emergência situamse em bairros como a Salina do Sacavém (Figura 6), Coroadinho, Vila Bacanga, Vila Isabel e Quinta dos Machados - bairros com população predominantemente de classe socioeconômica mais baixa -, considerando um número aproximado de 600 famílias presentes em tais regiões.

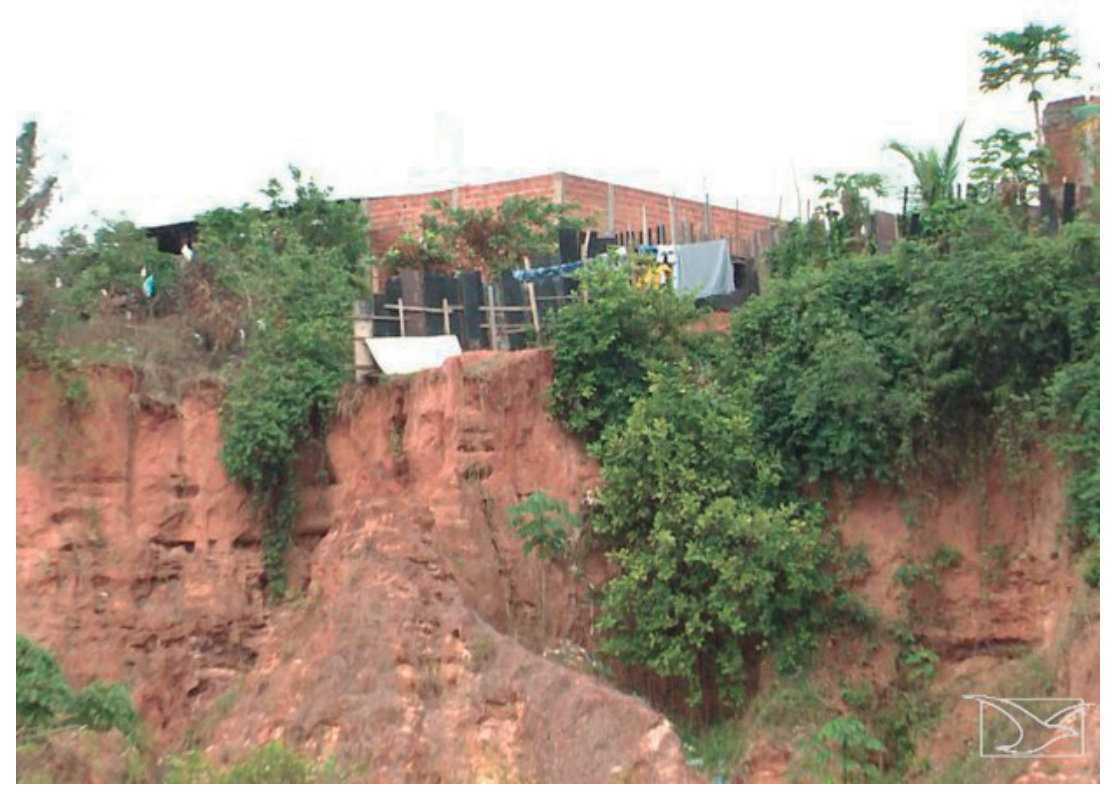

Figura 6: Área de risco em São Luís monitorada pela Defesa Civil (Sacavém). Fonte: Reprodução TV Mirante, 2016.

O mapa a seguir (Figura 7) apresenta a localização das principais áreas de risco no munícipio de São Luís por tipologia de risco: Desabamentos, Deslizamentos e Alagamentos (GARROS, 2016): 


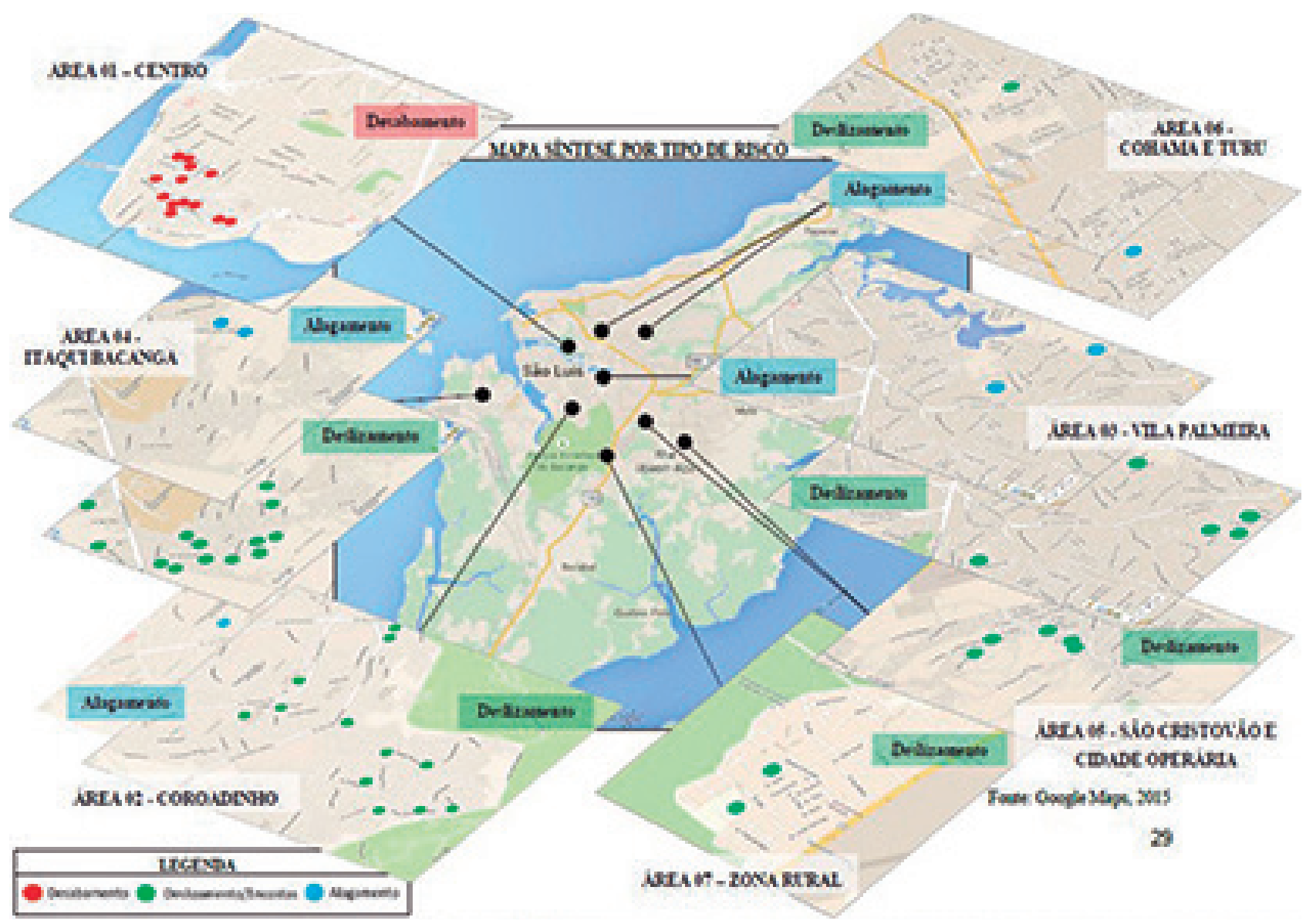

Figura 7: Mapa Sintese por tipo de Risco. Fonte: GARROS, 2016.

Dessa forma, alagamentos e deslizamentos constituem os principais riscos em São Luís. Além disso, tais riscos possuem uma problemática em comum tanto em bairros mais carentes como em bairros considerados nobres: a drenagem urbana. A ineficiente drenagem urbana maximiza as áreas de riscos e potencializa o surgimento de futuras áreas de risco na cidade. Embora grandes obras de macrodrenagem e microdrenagem tenham sido realizadas nos últimos anos, é notório que em períodos chuvosos surgem inúmeros pontos de alagamento na cidade (Figura 8). São apenas reflexos de sistemas inadequados de drenagem, cujos efeitos são ampliados com a grande quantidade de resíduos lançados nas vias são depositados nos fundos das galerias, reduzindo a capacidade de 

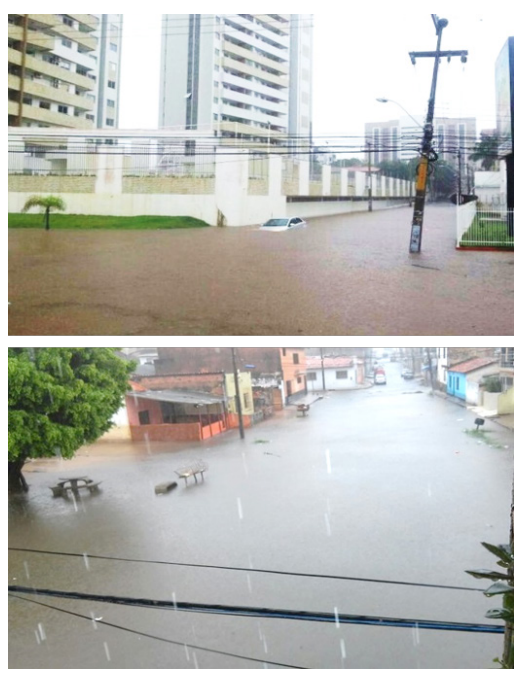

Figura 8: Bairros alagados em São Luís MA. Fonte: G1 Maranhão, 2016.
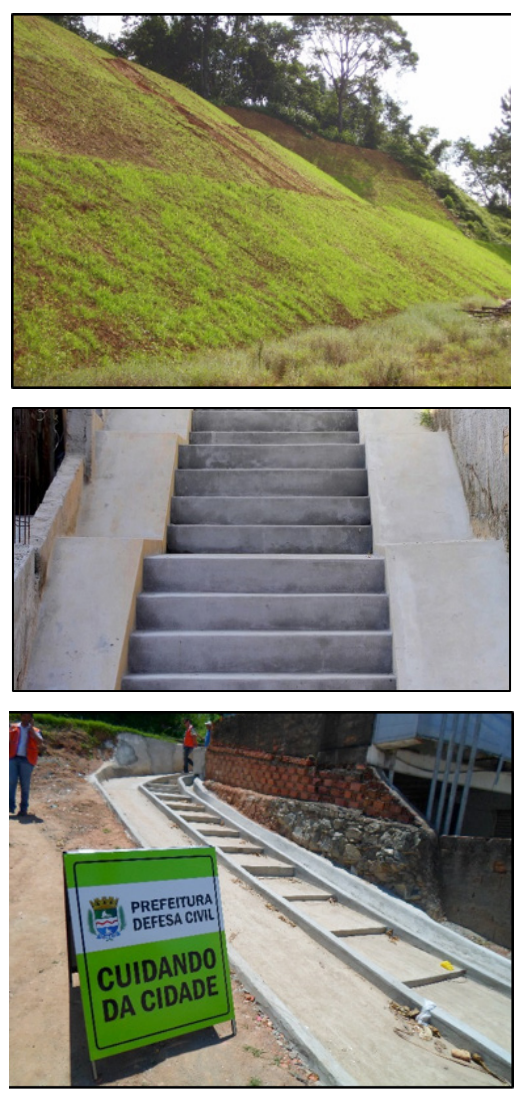

Figura 9: Soluções atuais adotadas em São Luís - MA. Fonte: Setor de Obras SEMOSP, 2015 vazão e dificultando o fluxo de água até as bacias hidrográficas. Somandose a isto, existem os dispositivos de drenagem que não suportam o volume das águas pluviais por serem rasos e/ou pela falta de manutenção, além do crescimento urbano desordenado que potencializa ainda mais o problema de escoamento das águas. A maioria das soluções adotadas em relação aos excessos do escoamento das águas pluviais em São Luís possui caráter corretivo e emergencial apenas em trechos pontuais do sistema, sem considerar o sistema de drenagem como um todo e priorizando as medidas estruturais e de alto custo em detrimento das medidas não estruturais e de controle (Figura 8).

Através das pesquisas realizadas nos setores responsáveis pela execução das obras nas áreas de risco, compreenderam-se os procedimentos tomados para tratamento e as soluções de engenharia executadas nestas áreas. Segundo as informações adquiridas com as entrevistas, a SEMOSP é o órgão responsável pelas situações de risco de desabamento - quando não compete às funções e responsabilidades do IPHAN - e, principalmente, pelos casos de riscos de deslizamentos (SEMOSP, 2016). Após o recebimento do laudo/solicitação da Defesa Civil, responsável por detectar o problema na área de risco, procede-se com o encaminhamento de uma equipe para fazer a vistoria geral do local juntamente do levantamento da área, para realizar uma análise de cada caso antes de qualquer obra. Assim como em outras cidades, nos casos de deslizamento em São Luís, são realizadas contenções com vegetação (taludes) para fincar as ribançeiras, constituindo-se de soluções econômicas, simples e eficazes. Outra solução utilizada nas áreas de encostas e terreno íngremes é a implantação de escadarias que auxiliam na contenção de deslizamento de terras e escoamento das águas superficiais (Figura 9).

\section{PERSPECTIVAS PARA A SUSTENTABILIDADE}

Argumenta-se a seguir a abordagem da resiliência das cidades e a as técnicas construtiva inerentes à Bioarquitetura como possivveis soluções para a redução de riscos aliada à redução da degradação ambiental.

\subsection{Cidades resilientes}

As soluções para cada área de risco devem ser analisadas minuciosamente, baseando-se na classificação dos graus de riscos existentes para verificação dos meios, locais e períodos adequados 
de intervenção. Uma cidade resiliente está apta a minimizar danos físicos e sociais decorrentes de eventos climáticos extremos e outras ameaças naturais ou induzidas pela ação humana, além de responder estrategicamente através de reconstruções e reestabelecimento de serviços básicos para retomada de atividades sociais, institucionais e econômicas após a ocorrência de eventos adversos (UNISDR, 2012). A resiliência de uma cidade consiste em mitigar e/ou antecipar os impactos dos desastres, inserindo tecnologias de alerta, monitoramento e alarme para resguardar a infraestrutura, bens comunitários e individuais, o patrimônio cultural e ambiental, e o capital econômico (Figura 10).

Diante do cenário atual, diversas secretarias governamentais do Brasil buscam soluções nas áreas de risco. No PDAP (Plano Diretor de Água Pluvial/Fluvial) do Estado do Espirito Santo (ES), há grande incentivo para a construção de edificações sobre pilotis e reforços, sistemas de previsão de cheias em tempo real e um possível plano de evacuação em casos extremos. Sobre as ações e intervenções que buscam a redução dos impactos negativos, destaca-se a necessidade de medidas de proteção individual das edificações em áreas de risco e sistemas de previsão de alertas. Portanto, observa-se um plano de ação urbana que não anula a convivência da população com os riscos, através de um plano de controle de águas que atenda às problemáticas reais existentes de forma eficaz (Secretaria de Saneamento, Habitação e Desenvolvimento Urbano do Estado do Espirito Santo, 2014).

Contudo, um dos maiores e mais óbvios entraves para quaisquer intervenções em áreas de risco são as restrições que as legislações pertinentes impõem como forma de controlar, planejar e orientar o crescimento da cidade, visando estimular o desenvolvimento urbano eficiente.

As áreas de risco em São Luís encontram-se principalmente em Zonas de Proteção Ambiental (ZPA1 e ZPA2), mas também em áreas legais para ocupação e construções ao longo da cidade, como em Zonas Residenciais. Ressalta-se ainda que com todas as restrições às áreas de proteção ambiental, é evidente que o estudo não estimula qualquer intervenção nas áreas de risco já determinadas pela legislação, mas nas áreas urbanas residenciais que já possuem a ocorrência de desastres em menor escala, em áreas suscetíveis a futuros desastres, além das áreas classificadas com baixo grau de risco.

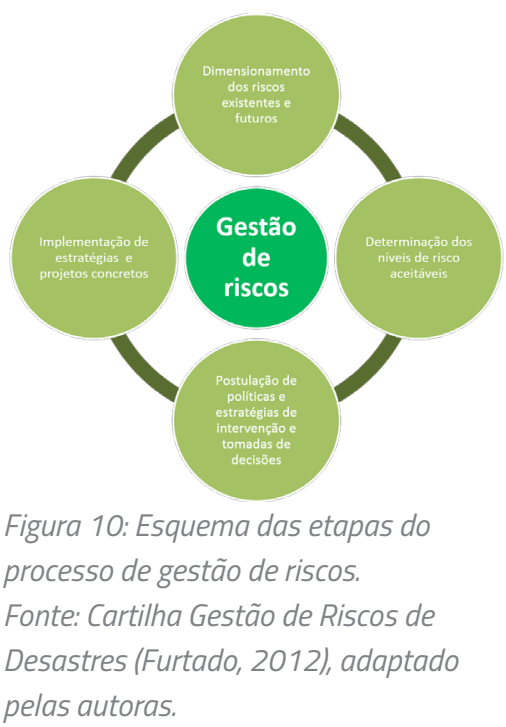

pelas autoras. 
Eliminar o risco pressupõe a remoção definitiva da população da área, o que nas condições de carência de áreas adequadas para receber a população e de recursos financeiros suficientes, não é comum se observar. A redução dos riscos pode se dar pela implantação de obras de engenharia. A convivência em níveis relativamente seguros se dá por meio da operação de sistemas de alerta ou planos preventivos (PARIZZI, 2014, p. 7).

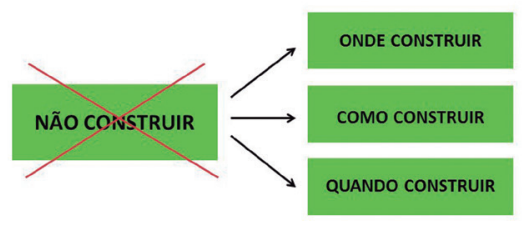

Figura 11: Esquema Justificativo para construção em áreas propícias a desastres. Fonte: Elaborado pela autora.
É essencial frisar que se justificam as intervenções em áreas de risco que podem ser realizadas de acordo com parecer técnico e soluções analisadas por profissionais - tais como geólogos, engenheiros, arquitetos, hidrólogos, geotécnicos, urbanistas etc. -, que apontem para uma construção que assegure a segurança e a qualidade de vida de seus usuários. Segundo Parizzi (2014):

Dessa forma, buscam-se soluções práticas para áreas de risco já ocupadas na cidade, tornando possível conviver com os riscos classificados com grau inferior de vulnerabilidade. Essa análise de viabilidade de intervenção vem sendo abordada em vários países, obtendo sucesso em seus resultados (Figura 11).

Sobre as habitações projetadas para resistir desastres, é válido destacar que devido às crescentes mudanças climáticas, o número de desastres tende a aumentar. Com a população mais concentrada em centros urbanos, é preciso investir em infraestrutura e edificações mais resilientes. Visto que tais fenômenos não devem ser mais tratados como eventualidades, é de caráter emergencial a proposição de Cidades mais resilientes.

\subsection{A BIOARQUITETURA}

Assim, como objetivo principal do estudo, apresenta-se a Bioarquitetura como uma alternativa adaptável às demandas da atualidade, flexível em seu funcionamento e sensível aos riscos ao aplicar técnicas que se interligam ao âmbito ambiental, econômico e social para a elaboração de projetos funcionais. A Bioarquitetura ganha espaço no âmbito econômico e social gradativamente, e cabe aos profissionais envolvidos no setor da construção civil impulsionar técnicas que estimulem a conservação e reaproveitamento dos recursos naturais.

Portanto, aponta para soluções habitacionais de baixo custo, com qualidade, durabilidade, mínima modificação do entorno, e integrando a edificação com o ambiente natural, tais como (Figura 12): Adobe, o Superadobe, o Pau a Pique, o BTC e o uso do Bambu na construção.

O Adobe é uma técnica construtiva tradicional vernacular que produz de forma artesanal um material de construção a base de terra crua, com barro e palha mesclados moldados em fôrmas por processo natural ou 
semi-industrial e, em seguida, secos de forma natural. Já o Superadobe ou "terra ensacada" é um processo construtivo que consiste em sacos de terra comprimida, isto é, o solo argiloso é colocado em sacos de polipropileno e moldados no local através do apiloamento.

A técnica do Pau a Pique também é denominada de taipa de mão ou taipa de sebe, e consiste na construção de um quadro de galhos: os verticais cravados no chão e os horizontais encaixados nos verticais. Tal quadro é preenchido por uma trama de bambus ou de galhos, sendo abertos depois os espaços para janelas e portas. Por último, os buracos da trama são preenchidos com argila.

O BTC (Bloco de terra comprimida) ou Tijolo de solo-cimento é um produto classificado como ecológico devido à sua composição, tratando-se de um bloco endurecido resultante da mistura homogênea e compactada de solo, cimento e água, sendo cada item aplicado em proporções adequadas (MOTTA et al. 2014). O BTC favorece a construção modular, otimizando tempo e recursos na execução da obra.

O Bambu dentro da construção civil pode ser utilizado como estruturas/ placas de vedação, estruturas de coberturas, piso, pilares e vigas etc. Dentre as muitas vantagens características do material, pode-se citar os seguintes aspectos: estrutura forte e rígida; uso de ferramentas simples para manuseios; material leve; superfície dura e limpa; estrutura flexível; e fácil transporte e manuseio. A inserção dessas soluções sustentáveis baseadas nos referenciais projetuais existentes apresenta alta eficácia.

\section{REFERÊNCIAS PROJETUAIS}

Após a verificação de projetos sustentáveis executados ao redor do mundo, que contemplem as diretrizes da Bioarquitetura, foram selecionados quatro projetos como referência. De forma geral, as soluções arquitetônicas mais adotadas em áreas com riscos de inundação e alagamentos são elevação (casas palafitas) e métodos para flutuação (casas anfíbias) das edificações (Figura 13).

As Houseboats (1) já utilizadas em várias partes do mundo, são construídas com matérias sustentáveis, são amarradas a uma doca, possuem regulamentação dada pelo governo e são ligadas aos serviços públicos
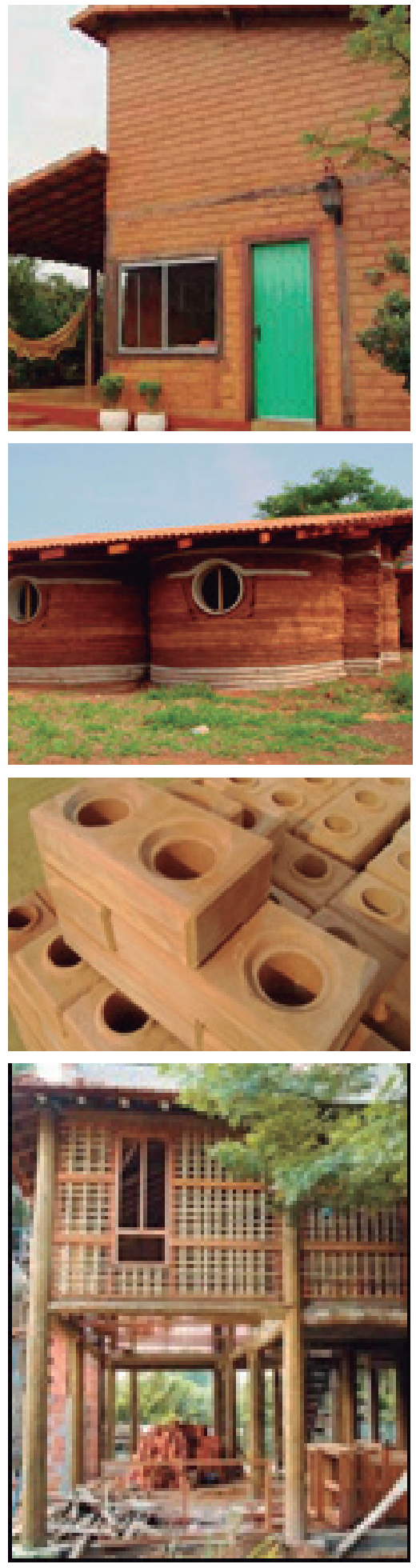

Figura 12: Técnicas construtivas da Bioarquitetura. Fonte: http://www.pensamentoverde.com.br/arquitetura-verdel. 


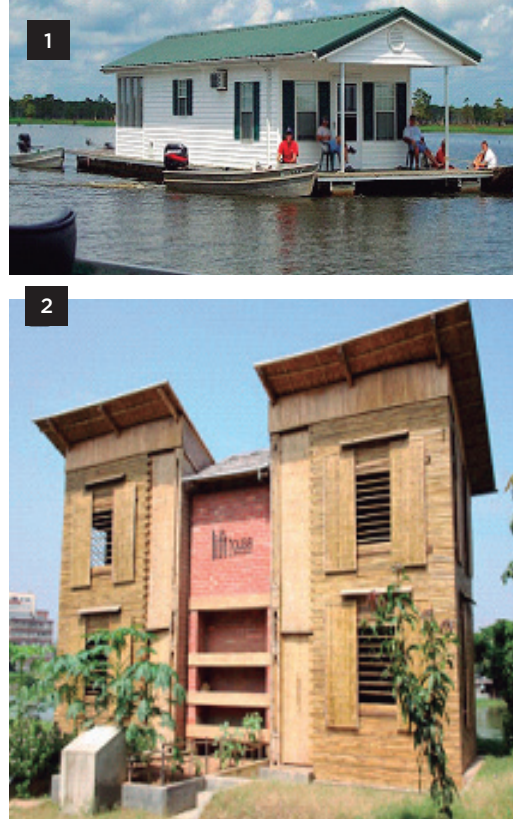

Figura 13: Referenciais projetuais Inundações e Alagamentos. Fonte: http:/l www.archdaily.com.br/. da cidade (energia elétrica, telefonia e rede de água e esgoto). As casas flutuantes funcionam como uma espécie de barco, podendo ser ou não motorizadas. Na maioria dos casos, as residências são construídas sobre uma estrutura de aço tubular, similar à utilizada nas balsas, o que garante que a habitação se mantenha estável e firme, mesmo com maré alta ou baixa.

A Casa Lift (2) ou Low Income Flood-proof Technology, que em português significa Tecnologia à prova de Inundações de Baixo Custo, foi projetada por Prithula Prosun para famílias que habitam em áreas de alagamento em Bangladesh. A casa flutua com o aumento do nível da água por meio uma base oca de ferro-cimento e uma fundação de bambu preenchida com garrafas plásticas vazias. Ao invés de bloquear o caminho das águas, a estrutura anfíbia da habitação se adapta à natureza para se proteger das inundações. A Casa LIFT é autossuficiente, sem conexões com os sistemas de abastecimento da cidade, visto que a habitação projetada proporciona os serviços básicos aos seus usuários durante o ano inteiro, gerando mínima interferência ao seu entorno. Vale enfatizar que o projeto piloto funciona como lar de uma família de cinco pessoas, após ser colocado à prova em janeiro de 2010.

Para as áreas com riscos de deslizamentos de terra - sendo este um fenômeno provocado pelo escorregamento de materiais sólidos ao longo de terrenos inclinados -, também se apresentam soluções por meio da elevação de habitações ao possibilitar a redução de desastres em terrenos íngremes, áreas de encostas e relevos acidentados (Figura 14).

No Equador e Peru, a proposta de habitação elevada (3) funciona de forma eficiente para abrigar as pessoas menos favorecidas socioeconomicamente devido ao baixo custo de execução. 0 elemento construtivo principal é o bambu e possui uma área de $9 \mathrm{~m}^{2}$. Projetada para até cinco pessoas, no pavimento superior situa-se a área social e no pavimento inferior existe o banheiro e cozinha. A casa possui uma fundação com solidez e resistência estrutural. Embora a parte inferior seja feita de betão, o restante da construção é executada em bambu e madeira. Em 2009, esta proposta equatoriana de habitação foi premiada por um concurso internacional, pois tais casas elevadas de bambu estrategicamente se adaptam às mudanças climáticas. 
Já as casas projetadas na Îndia (4), sustentadas por estacas de bambu, permitem a fixação no solo sem a movimentação de terra (cortes ou aterros), que costumam destruir a estrutura do terreno. As habitações de três andares feitas de bambus foram projetadas por arquitetos indianos, teve como objetivo criar uma comunidade ecológica com unidades habitacionais compostas de coleta de água da chuva, reutilização de água, plantações e espaço comercial.

Existem muitos outros exemplos práticos de habitações que se adequaram a um relevo bastante acidentado sem estimular deslizamentos de terra ou que são resilientes à alagamentos e inundações. Os estudos realizados através das referências projetuais expressaram a necessidade de repensar as medidas adotadas em áreas de risco na cidade de São Luís, especialmente afetadas por alagamentos, inundações e deslizamentos de terra. Portanto, tais referências criam premissas para a busca de soluções que visem não uma replicação de métodos, mas uma aplicação adequada de técnicas de mínimo impacto ambiental à realidade local.

\section{CONCLUSÕES}

Uma cidade resistente precisa ser adaptável, e para ser adaptável, o ambiente construído pelo homem precisa também ser inovado com frequência. De forma geral, nota-se a emergencial atuação preventiva de iniciativa pública e/ou privada, que propicie às famílias que moram em áreas de risco condições de "conviver com os riscos em segurança". Como visualizado nas referências projetuais, isto é possível através de propostas de habitações eficientes com mínimo impacto ambiental.

Assim, o artigo busca estimular a fomentação de pesquisas cientificas futuras que contribuam métodos e técnicas que evitem ou reduzam o número de perdas de vida humanas e de bens materiais decorrentes dos efeitos dos desastres naturais existentes, bem como àqueles suscetíveis a ocorrer no futuro nas áreas consideradas de risco. Consequentemente, promove-se a reflexão sobre o papel da arquitetura como ferramenta de melhorias do espaço habitado e a construção cidades mais inclusivas, seguras, resilientes e sustentáveis.
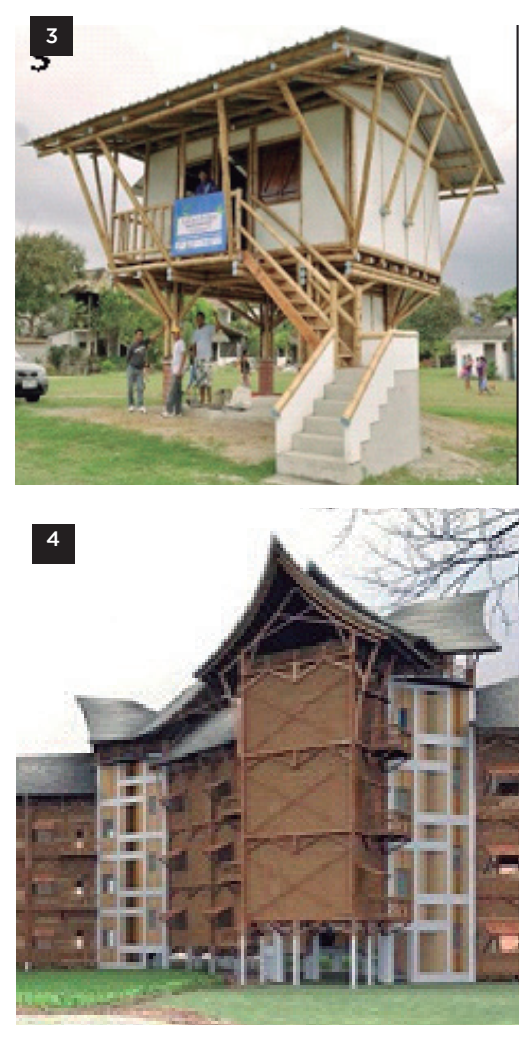

Figura 14: Referenciais projetuais - Deslizamentos. Fonte: http:// www.archdaily.com.br/. 


\section{REFERÊNCIAS}

Áreas de riscos em São Luís. Entrevistas. Defesa Civil Municipal, São Luís, 2016.

Casa Lift. Disponivel em: https:/www.archdaily.com.br/br/01-151698/casa-de-bambu-embangladesh-flutua-em-caso-de-inundacoes>. Acesso em: 10 de fev. 2016.

Casa Indiana. Disponivel em: <https:/www.archdaily.com.br/br/01-125736/arquitetosindianos-criam-predio-de-bambu-resistente-a-terremotos>. Acesso em: 10 de fev. 2016.

Casa Houseboats. Disponível em: <http://gaarq.blogspot.com.br/>. Acesso em: 9 de fev. 2016

Casa Equador. Disponível em: http://www.larevista.ec/actualidad/vivienda-y-decoracion/casaselevadas-de-cana-guadua. Acesso em: 25 de jun. 2016

Desabamento de casarão no Centro Histórico de São Luís. Jornal O Estado do Maranhão, São Luís.

FURTADO, J. R. Cartilha gestão de riscos de desastres. Centro Universitário de Estudos e Pesquisas sobre Desastres. Florianópolis: CEPED UFSC, 2012.

GARROS, EDITH M. M. Bioarquitetura: sistemas produtivos de mínimo impacto ambiental aplicados ao planejamento de habitações em áreas de risco. São Luís, 2016.

GAUZIN-MÜLLER, D. Arquitetura ecológica. São Paulo: Senac, 2011.

Instituto Brasileiro de Geografia e Estátistica (IBGE). Dados 2017. Disponivel em: <https:/ cidades.lbge.gov.br/xtras/perfil.php?lang=\&codmun=211130\&search=||infogr\%E1ficos:informa\%E7\%F5es-completas>. Acesso em: 25 de ago. 2017.

G1 Maranhão. Com chuva, Defesa Civil faz ação e monitora áreas de risco em São Luís. Disponível em: <http://g1.globo.com/ma/maranhao/noticia/2016/01/com-chuva-defesa-civil-faz-acoese-monitora-areas-de-risco-em-sao-|uis.html>. Acesso em: 26 de jan. de 2016.

LAVELL, A. Degradación ambiental, riesgos y desastres urbanos. Problemas y conceptos: Hacia la definición de una agenda de Investigación. Disponível em: <http://www.desenredando.org/ public/libros/1996>. Acesso em: 10 de mai. 2017.

MOTTA, J. C. S. S.; MORAIS, P. W. P.; ROCHA, G. N.; TAVARES, J. C.; GONCALVES, G. C.; CHAGAS, M. A.; MAGESTE, J. L.; LUCAS, T. P. B. Tijolo de solo-cimento: análise das características físicas e viabilidade econômica de técnicas construtivas sustentáveis. E-xacta (Belo Horizonte), v. 7, p. $13-26,2014$.

Palafitas na Liberdade. Jornal O Imparcial, São Luís.

PNUD - Programa de las Naciones Unidas para el Desarrollo. Dirección de Prevención de Crisis y de Recuperación, 2004. Disponível em: <http://www.undp. org/cpr/disred/documents/>. Acesso: 12 de out. 2017.

SATTLER, M.A. Desenvolvimento Urbano. Habitações e Construções Sustentáveis no Brasil. Disponível em: <http://www.usp.br>. Acesso em: 10 de mai. 2017.

UNISDR (2012). Como construir cidades mais resilientes - Um guia para gestores públicos locais. Genebra, Suíça: Escritório das Nações Unidas para Redução de Riscos de Desastres.

VAN LENGEN, J. Manual do Arquiteto descalço. Editora Empório do Livro: São Paulo, 2008. 